\title{
Exploring the Preparedness of Ghanaians for Retirement and Ageing: A Case Study of the Cape Coast Metropolitan Area
}

\author{
Irene Korkoi Aboh ${ }^{1, *}$, Busisiwe P. Ncama ${ }^{2}$ \\ ${ }^{1}$ University of Cape Coast \\ Ghana \\ ${ }^{2}$ Divisional Vice Chancellor, College of Health Sciences, Howard College Campus, University of KwaZulu-Natal \\ Durban, South Africa \\ *Corresponding author's email: iaboh [AT] ucc.edu.gh
}

\begin{abstract}
-----
Introduction; There is evidence of the inability of older people in Nigeria, Ghana and other developing countries to sustain themselves through savings, assets or pensions. This situation highlights the minimal benefit of pensions, savings or assets as income sources for older people; old age very often brings poverty and disability.
\end{abstract}

Methodology: A qualitative interpretive design informed the study. The study area was categorized into three distinct ecological areas namely urban, periurban and rural areas. Twenty interviews and three focus group discussions with 68 elderly persons were conducted in ten sub-districts in the Cape Coast Metropolis, Ghana. The forty-eight elderly individuals were put into groups of 8,20 and 20 for the focus group discussions. Data was thematically analysed.

Results: Four major themes and subthemes were identified to reflect the pertinent issue of exploring and defining the preparedness of people for their retirement and ageing. There was evidence that preparing for old age is not an active precedent for the people of Cape Coast and they still believe in the traditional system of caring where it is the sole responsibility of the family to care for its own aged members.

Conclusion: It is evident that formal care is not practiced in Ghana and that the aged therefore find the idea bewildering. They want to experience this care, but existing norms expect the family members to single-handedly provide care for their aged.

Keywords--- Aged, assisted care, informal care, traditional care, Cape Coast

\section{INTRODUCTION}

While the average age of populations continues to increase ${ }^{1}$, increasing numbers of people are spending one-fourth of their life course in retirement ${ }^{2}$. Lee (2003) attests that the feeling that one is in control of his/her life is seen as a determinant of well-being in elderly, and an important characteristic of successful ageing and planning. Retiring from one's primary career job represents an important life event, marking the transition from one life stage to another ${ }^{3}$. One third of retirees experience the transition as stressful or a decline in well-being after retirement. A school of thought advocates that age 40 is the time for individuals to start thinking about retirement, based on the old adage that "life begins at 40", and recommends that workers should begin to think about retirement the very day they become employed ${ }^{4}$. Large variations in retirement wealth are common, with some households accumulating more than others ${ }^{5}$. Retirement planning is a complex phenomenon or process that takes place over time; it involves a series of reflections, decisions concerning the timing and form retirement ${ }^{6}$.

Planning for retirement

Few people engage in advance care planning discussions with their families, substitute decision-makers and healthcare providers before pension ${ }^{7}$ because of this households differ markedly in their wealth accumulation for retirement and budget constraints, information ${ }^{8}$. Behavioural-economic models imply that people generally undersave, and undersavings may also arise due to exponential growth bias ${ }^{9}$. According to the traditional economic theory those who plan for their lives get older than those who do not, individuals who have full information on pension are able to process this information for rational decision making ${ }^{8}$. 


\section{Formal sector}

In the African region, policies are built on the assumption that private networks, communities or families can shoulder the burden of care for older persons, sometimes overlooking limitations in the capacities of family care givers, who are mostly women. The impacts of such unpaid work on the quality of care, income of care families, and the health and future employability of caregivers is yet to be established ${ }^{10}$. Financial planning is a major significance of both private and public policy makers ${ }^{11}$. Current information on the sources of income in developed and developing countries show that, the richer the country, the higher the percentage of those above the age of 60 relying on pensions/welfare for their livelihood. It is also noted that as countries get richer, formal system gain importance in providing support to the elderly ${ }^{12}$. Advertisements from financial service and counselling firms are seen on billboards, televisions, and in print and electronic media, seeking to create public awareness and capture audience attention about the importance of planning. Personal retirement planning is not mandatory, but rather an option in financial preparation and management; it is partly based on the strategy in which personal income is allocated for savings, investments, and spending. Unfortunately, not everyone is ready for this plan ${ }^{13}$. They noted that not all are financially prepared for their post working life because they either have limited savings or do not have enough assets to generate that level of income. According to the 2007 Retirement Confidence Survey ${ }^{14}$ in United States, only $66 \%$ of workers save for retirement, yet in most cases the amount is insufficient.

In Sub-Saharan Africa, coverage by statutory social security schemes is very limited and largely confined to workers in the formal economy and their families. Some workers rely on employer-provided benefits which they do not receive; others also receive retirement income from defined benefit pension plan as retirees. Public sector workers depend on pension income more often than those in the private sector, and there is a higher level of defined benefit pension support in the public sector ${ }^{14}$. To enhance smooth transition into retirement and curb associated problem employers have adopted programs for future retirees, by promoting better employee relations, reduce resistance to changes, and helping workers make adequate preparations for post-retirement ${ }^{15}$.

\section{Informal sector}

Family is a much more important source of income for the elderly in Africa than elsewhere in the developing world. The informal systems are based on broader familial links, the extended family could contain adult brothers and sisters as well as children. Practices of adoption, fosterage, and raising grandchildren all help to widen support base. Another source of informal support in Africa is the existence of kin, community and tribal support ${ }^{12}$. There is only one thing a person can do which shows more love and brings more respect than building a house; this is by giving his children a good education and enabling them to acquire proper jobs. By doing so, a man is 'building' his own future security ${ }^{16}$.

\section{METHODS}

The study adopted a qualitative design. Data was collected between October and December 2016, it included 20 in-depth interviews and 3 focus group discussions (FGDs) with the aged (65 years and above) from ten sub-districts in the Cape Coast Metropolitan Area, Ghana. The study received ethics approval from the Dodowa Health Research Board from the Ghana Health Service (approval number DHRCIRB/06/06/16) and the Humanities and social sciences Research Ethics Committee of the University of KwaZulu-Natal, South Africa (approval number HSS/0608/016D).

\section{DATA COLLECTION}

Out of 25 sub-districts in the study setting, 10 were randomly sampled. These selected communities were categorized into three ecological zones: urban, peri-urban and rural. The urban zone signified areas where existing social amenities were the best, the peri-urban zone categorized communities that looked either urban or rural, then the rural zone was areas which lacked most of the social amenities. A proportional to size sampling was employed looking at the respective population densities of the three zones. A potential sample of 162 aged was identified to be used for the study after redefining the aged to be 65 years and over, because those in the category 60-64 years were still very strong and in active work force; the decision was accordingly made to confine participants to those who were frail, tired, and living with or without a caregiver. 20 aged participants were visited for one - on - one in-depth interviews from the 10 sub-districts and a FGD from each of the ecological zones making up of 8 participants from the urban community and 20 each for the periurban and rural communities respectively. Snowball sampling technique was used in selecting the aged. One aged person was identified by an informant for the interview and that aged person then purposively selected the next aged person to be interviewed, thereby satisfying the snowball techniques. FGDs were then organized with other identified cohorts. Duration of the in-depth interview and focus group discussions was between 20-60 minutes using key prompts.

Table 1 Study sites and activities

\section{DATA ANALYSIS}

All interviews and focus groups discussions were transcribed verbatim according to participants and sites. The principal investigator (PI) and her research assistant, along with the co-author read all the transcribed documents and together 
discussed the broad themes that emerged from the data. The PI and co-authors then read all the data in each theme and agreed on them, confirming four major themes and four sub-themes. The themes were iterated and guided by Maslow's hierarchy of needs and the SWOT analysis to assess assisted care. The authors then discussed the identified themes to confirm relationships between themes.

All the ten sites were near each other, except two ( 8 and 9) that were hard- to- reach areas. At the commencement of each interview or FGD, participants were helped to relax by explaining the reason for the presence of researchers. Participants and head of households were given consent forms to read and sign for inclusion in the study. Caregivers were assured of needed assistance but asked not to criticize the input of their wards. Participants were open and ready to give pertinent information about themselves when they realized the reason for the meeting was to find out about their care. They explained in detail what the community thought of their care, how they wished they could have done some things when they had the opportunity and how they will do things differently if they could turn back the clock. Four major themes become exclusively evident: (1) preparedness for pension and ageing, (2) awareness of government policy, (3) adequacy of current caring system, and (4) interest in assisted care.

\section{RESULTS}

\section{Theme 1: Preparedness for pension and ageing}

Participants were between 70 and 98 years old. None of them had consciously planned for their retirement and old age. Seven participants were government workers and had gone on pension but do not know what it entailed nor, could they explain how it worked. They appreciated the fact that at the end of every month they received some money to buy food. They came home because it was time to retire. Two of the participants had been in disputes with their superiors and had resigned from work out of anger and travelled abroad to look for greener pastures. As one participant stated,

I was the higher executive officer by then, I am not on pension... I was framed and given kangaroo ruling. (Site 4, male, 81 years).

The second participant said

I was compelled to leave the Police force so I did not wait for pension. In 1980, I went to Nigeria to look for greener pastures. I just came back last year; ... for now, only one boy [his son] is looking after me... the rest have abandoned me; my savings is now finished. (Site 1, 80 years).

One participant stated that

I am on pension that is cap 30... I don't know how to explain the cap 30 or how it works but at the end of every month ... I am given something.

Those who were not government employees were petty traders, fishermen or fishmongers. One had this to say:

I did not go to school, all I did was to help my husband with his fishing business ... he did all the planning; I was just living the time .... It was my husband's responsibility to plan for us, but he is gone so where God put me is where I am ... I am waiting for death. My children are all scattered. It is my last born who is here with me looking after me ... I am just waiting to die and join him. (Site 7 \&, female 98 years).

One participant said her plan was to come home and live where her umbilical cord and placenta were buried after baby making.

I was born and brought up here ... my placenta was also buried here... this is my birth home... so I decided to come back and live here so that people will not call it a deserted home or haunted house. (Site 10, female 78 years).

From the FGDs one participant said,

Planning is what we are lacking in Ghana, .... we hardly get this training or advice when we are growing up or when we are employed .... We don't have that direction for retirement when you enter the job market ... we don't know how to do it ... with the public sector or for some security services as soon as you are recruited they are given the notion that appointment is for a period, so you must prepare for existing ... so they educate them on financial security. ... At a certain point in time you must move out of the barracks. ... You make compulsory savings .... And when they see that you are getting to the end of the service, they come to find out what preparation you have made especially towards retirement. (FGD2, Site 5, male).

\section{Theme 2: Awareness of government policy}

All participants responded that they did not know of any government plans for the aged. In the FGDs only one participants remembered that government had a policy for a subsidized National Health Insurance Scheme (NHIS) for the aged where they renew their cards on a free premium basis.

The government should have a plan for the aged ... we are not aware of any plan apart from the pension scheme. (FGD1, Site 1, male), We had ideas of some plans e.g. the NHIS and the amount for renewal-apart from this nothing. (FGD2, Site 5, male)

\section{Theme 3: Adequacy of current caring system}

Sub-theme 1: Welfare

Preserving basic physical and material well-being was a priority for all participants. They all commended themselves for still being strong and able. All of them said they went about their activities of daily living without difficulties such as 
personal hygiene, laundry and were part of daily planning in their homes except for those living alone, it was the people around them who oversee housekeeping, preparation of food, visiting the hospital, using the telephone and leaving the house. Some eventually no longer went anywhere and relied on what they got from benefactors. One participant reported that

I live with my children ... they do their very best. And I very much appreciate what they do for me. (Site 10 , female). $\backslash$ My grandchildren take care of the house chores. I don't do anything. (Site 1, male). I My children provide me with money but it is not enough. It lasts for just few days because it varies, when it gets finished; you stay like that no food until money comes again. (Site 6, female).

Sub-theme 2: Actual residence

Participants were found to be either living alone or staying in the residence of a relative. Some participants were living alone in their own residence. Those who were government workers had their own residence which was government allocated. Aged living with relatives were living with the second, third or fourth generational family, so caring was a collective responsibility. Nobody was assigned solely to care for the aged, and these aged seemed to be well catered for. Some participants had held on to where they are living without seeking another companion; although their husbands had died very early, and they could have remarried, but were afraid of losing their homes to their husband's extended family. A participant had this to say,

The house is for my late husband so that was the only legacy we had, because you know women are not allowed to own a property. ... My children were very small when he died, if I had remarried I would have lost the place to my husband's people; I had nowhere to go so this was where I planned to stay after his death. (Site 2, female)

Another participant reported that

I am a tenant in this place ... it (house) belongs to someone else ... in fact, my husband rented it so when he died I am left here alone. (Site 2, female)

In another group,

I live with my grandchildren ... when I need something ... they help me ... we do not do any difficult work again ... it is our grandchildren ... some are to be in school (FGD 3, Site 5, female)

\section{Theme 4: Assisted care}

Discussion on institutional care generated a heated deliberation among participants. It brought out four subthemes: caretakers, funding, cultural disposition and intent for programme.

Sub-theme 3: Caretakers - the ages of caregivers for participants who had people staying with them, ranged from 8 to 72 years, and they were their children, grandchildren, nieces, engaged family members who were not paid for their services. These participants were residents in their own home or their children's home. One participant with a niece wished she had an older caregiver to take care of her but could not afford such services and said that if she were to ask her children to pay for such services they would all ask her to come and live with them.

None of my children lives here currently but I live here with my niece. She was abandoned by her mum and I took her in ... I cater for myself from selling my wares. I wish I could use the services of a matured caregiver, but I cannot afford the fee. (Site 10, female).

Other responses from interview participants are listed below,

I stay with my children ... two girls ... my children are 5 in all ... I live with these two for now. (Site 2, female) $\backslash$ I have my granddaughter who also comes to visit me and stays with me now and then. (Site 4, male) I I am 91 years old woman and I live with my daughter who is 70 years. This house is for her ... she does everything for me. (Site 2, female) \I am staying with my grandchildren. One has just finished the University, so I do not have a caretaker ... they are both boys and students. they are 31 and 24 years old. (Site 3, female) $\backslash$ I stay here with my grandchildren ... 2 boys from my step-daughter ... they are 24 and 22 respectively. (Site 1, male) $\backslash$ live with my son, but he doesn't stay home ... my granddaughter, her husband and children look after me, but they are in the next village ... so currently I am alone. (Site 8, female)

Participants in the FGDs reported that they were cared for by relatives who were either a biological child or an extended family member.

My granddaughter is there; she is 8 years .... And my 30 years old daughter also is here ... they do everything for me $\backslash$ I live with a granddaughter too ... she has just completed her basic education $\backslash$ I stay with my children ... 2 of them. (Grp 1, site)

Another group expressed their sentiments about caring as follows;

Nobody pays anything \some of the caregivers are relatives $\backslash$ caring becomes a family issue $\backslash$ it is not that you planned it like that ... it is in rare cases that you hear people have hired caregivers $\backslash$ it is not a practical thing in our area here. (Grp 2, Site 5). $\$ Hiring caretakers are very few ... it is not done here .... for people to request from others to come and take care of their aged parents because they are indisposed $\backslash$ it is very queer ... my mother is very old ... incidentally the person looking after her is my own brother and I am supporting him to cater for our mother. We find it difficult to relinquish our responsibilities to others when it comes to caring for our parents $\backslash$ more so if you are not at a certain level .... Caring for the nuclear family is a problem and very difficult. (Grp 2, Site 5) 


\section{Sub-theme 4: Funding}

When participants were asked how the programme was to be funded, some indicated a preference for the programme to be handled by a private entrepreneur rather than by government, claiming government-run programme do not last. The programme should be funded by individuals, families and government. A participant felt that the researcher should use her initiative to organize and look for sponsorship for the programme:

That is once you set up this kind of programme, it means you will be able to manage it on your own. You must look for a venue and NGOs to help ... it should not come from the relatives or aged ... they themselves have headaches ... any way I cannot speak for them ... how can I hold brief for someone somewhere (Site 3, female).

I think all my children will contribute and pay ... I have also got a means of saving (referring to the means of selling iced water) or doing something ... We (Anglican) community planned to do this thing but that was a long-time age and it fissile out. (Site 5, female)

Another participant expressed dislike for an assisted care:

Our environment is not like the Overseas ... up there it was started with their generation so they are used to this kind of programme but here ... Are you about to start? .... You can start but am not interested ... I will not go but I think the day care will be good for our environment ... I heard money is involved. (Site 10, female). She added as an afterthought, Yooo! ... I have heard ... but it will be a very good experience for Ghanaians. God bless you for this idea ... thinking about it now ... I think it is a good idea ... some of my counterparts in the village here have no caregivers. How to even warm their food is a problem .... so please do something about these issues for us ... But please take into consideration the issue of doctors and nurses to look after us in our homes.

Funding was a troublesome concern with FGD2; participants were initially uncertain how to respond, then began encouraging each other to talk:

People please talk ... what we are discussing concerns all of us ... speak English if you like or speak Fanti (local dialect) (FGD2, Site 5, male) \Well, this idea is a laudable one ... bringing this type of caring for the aged to our door step ... it is a good idea ... However, this our community is a very deprived and a poor one ... eating is even a problem for majority of us .... So, if this programme requires payment of money .... where and how are we going to get this money? .... Some of our children are unemployed so when it comes to the issue of money ... it will be very difficult for us .... we will have to think about this well .... we should not rush now ... let us think about it well because it will involve some money. (FGD2, Site 5, female) $\backslash$ Please come and do this project ... we have a lot of land ... and we will lobby the chief to give it to you for free... you are coming to help the community ... so please you are welcome. Please is someone writing names ... please put down my name. (FGD2, Site 5, male) \How can you speak for us ... we are going to ask our children. (FGD2, Site 5, male). I Since we are all pensioners on allowances ... the youth must start paying monthly contributions towards their aged period for this programme. ... funding must be from the individual, but government must subsidize the cost ... the children will also support. (FGD2, Site 1, male) \... I think government should come in ... just like the social security this will be something like that for us ... so that at the end of the active tenure ... gratuity will reflect in it. (FGD2, Site 5, male)

Sub-theme 5: Cultural disposition

The sense of culture as an attribute of participants was captured in the way they refined their thinking and mannerisms. Every word of the PI was attentively listened to and given critical consideration. Participants were quick to conclude on how the community would react to people ready to live in an institution for provision of care. One participant commented that

We are not brought up like that, so it sounds funny. (Site 4, male)

Another participant made the following extended comment:

The aged too must be remitted for their maintenance. It will be proper than an institution style. This place is not like the Whiteman's country ... but Ghana ... looking at things would it work?... People who are frail will love to do this thing (laugh) ... but I think the government should make it a duty to be giving something to the aged ... it will be better than camping them in an environment ... (laugh)... the story is very interesting ... I am amused. (Site 10, female)

Another participant opposed the proposal by offering his services whenever necessary in assisting with caregiving for another participant's mother:

So, as you said your old lady is closed by, don't worry we will support you to care for her ... occasionally we will come to your house to care for her. For my mother we keep showing our responsibility towards her ... she goes to one person for a while and then to the other another time. But not to be looked after by someone $\backslash$ but you remember he said his brother looks after their mother not an outsider (interrupted) $\backslash$ No I didn't get an outsider ... if I had ... I would have made use of it ... there is one happening here ... my neighbor ... that woman is even not too old, but her children have brought in a caregiver ... these things happens but not very often. (FGD2, Site 5, male) 
Sub-theme 6: Intentions if the programme was established

Participants indicated strong disapproval of the concept of assisted care until they were given the pros and cons of it. The majority then thought it was a laudable idea, wanted it to be introduced in Ghana, and would be willing to enroll, but were skeptical about what community members would say. They also thought government should contribute towards the cost of their upkeep since they had once contributed to the country's economy when they were active. They complained bitterly about not being given anything as pension now that they were no longer strong enough to work. Below are a few of their concerns;

Whoo!! It is a good idea and Ghana should also adopt it. Because someone like me if it had not been that I have people around me... I will be part. (Site 4, male). The government should have a plan towards the aged... In the family houses... there are a lot of problems ... so the elderly will prefer the aged home. In Ghana, we are so much attached to each other to the extent that getting separated is a problem for us. (FGD1, Site 1, female) I do not think it is a total seclusion kind of thing ... you can go and eat with her in the home and come back to your home ... others can go there on regular basis (FGD2, Site 5, male)

Hmm .... That sounds funny (laughs) I think when I am weak I will consider that option and if they will take good care of us why not? ... The daycare sounds very interesting and I am interested in that one because I feel very lonely and bored most of the time... Government should do something about the programme (Site 4, male). I...it will make government look at us and help a lot of our colleagues out here. A lot of us are very miserable. I cannot go and stay there because of my predicament (daughter and grandchildren) .... My daughter will be stranded without me but will prefer the daycare. Government should be kind to us (aged) by giving us something small as pension because we have really worked hard as fish mongers at the beach here .... Some of my colleagues really need help because they have become disabled and have lost their children. (Site 6, female).

No, I have not heard of anything like institution before. For now, I am not too strong to do anything ... ohhh! I am very interested ...I will want to attend that of the daycare so that I hang around with my peers. My daughter will be the one to take care of payment if I should attend .... I think it is the duties of the relatives to pay for their wards' upkeep. (Site 9, female)

A participant living with a grandchild said he had known he would be on pension one day but had not expected to live this long

My grandson looks after me, he is 9years ... My daughter does my cooking on weekly basis .... Will there be caregivers and people my age with nurses 24/7?... Is money involved? I think my children will pick up the cost because I don't believe in programme controlled by government. If there will be a way to visit the shed, I will love to be part of it .... Yes, you (pointing at the P1) will have to bring this to Ghana. I knew I will one day be on pension but I did not know I will live this long and be this old. (Site 3, male)

One female participant wholeheartedly accepted the concept and quickly spelt out some of the benefits she envisages I have heard about the aged home ... It will be very nice to go there. Just meeting with your age mates ... talking and laughing together .... It will be fun .... it will not make us think of unnecessary things .... You will just forget about your sorrows (Site 5, female)

Another participant also thought it was a good idea;

Yes.... This issue of caring should be established in the Central region. ... A lot of the aged are very old and frail but still working to take care of themselves. .... you can see all is not well but still she is carrying very heavy loads for sale. There is a woman next door .... She will bath and groom well but will come and look for alms so my daughter has to give her some of the food and that is what she eats the whole day. (Site 2, female)

Among others expressing approval, one participant felt that setting up a home for aged was a long overdue development for Ghana

Ghana has come a long way and it is long overdue for this programme. Because ...Ehhhmmm .... (a big sigh) an assistance or two from somewhere will be good, because some of them do not have a place to live. ... For me it will reach a stage I may not have because I look up to my grandchildren for help sometimes. ... Looking at it personally, I need some assistance. Yes .... Government should bring up something like this. (Site 1, male)

If the government want to provide us with this programme or help us ... that will be nice, but they always promise since I was a young man and they do nothing. If this institution is set up and will require payment, my children cannot afford it. I really would like to be there .... Seeing colleagues and having little fun is good (Site7, male)

One participant felt that assisted care services should be extended to individual homes;

Really!!! When is this programme starting ... that is a good idea but now I am very old. .... I have few days to live so why not allow the nurses and doctors come to look after me at home? .... I will prefer it here. ... You people can come and give me attention once a while in this house ... so that my grandchildren can come home. That is how I feel ... this house is their roots and they must come home. (Site 9, female). 
Assisted care .... Laugh ... it will be better if the aged are cared for in their own homes ... the caregivers (nurses or doctors) .... So that we can contribute to augment what government will give them (Site 10, female).

Identifying themselves as custodians of culture, some participants of the FGD expressed strong disapproval of assisted care even after the PI used the SWOT analysis approach to explain what assisted care was. They argued that living elsewhere or bringing an outsider to their homes would be a disgrace, but later a fraction whole heartedly accepted the concept. Others who thought the programme was already in existence said they would need permission from their children to enroll.

I have children who are to inherit their father through me ... (FGD 3, Site 1, female) \for me I am hearing of this for the first time ... I must talk it over with my children ... sell the idea to them first ... but I have no wish to leave my home and stay elsewhere. (FGD 1, Site 1, female)

I will prefer the day care aspect ... because it is lonely when the children leave for school. (FGD 2, Site 5 female) $\backslash$ I have to discuss it with my children so that we collectively decide on what to do ... we have to listen to our children before we make a decision ... so I will suggest we meet again on this issues ... if I decided to go for the assisted care because I can personally pay without my children consent I cannot go. (FGD 3, Site 7 , female). $\backslash$ This matter in fact is a difficult one. What will people think of my children? It will look as if they do not want me around, so they gave me a push over. (FGD 3, Site 7, female)

The Coordinator reminded the group that some people did not have children of their own and therefore needed caretakers. A participant quickly affirmed this and added, Oh! We have a lot of them ... I am one of them ... I roll kenkay (local food) for a fee. (FGD 3, female).

\section{DISCUSSION}

The study showed that planning for retirement and old aged had been done unconsciously and therefore not done well. Women in active marital unions either looked to their husbands to do their retirement planning or did not plan financially for their old age; this is in line with the belief that retirement and retirement planning is in the male domain and positions women as unconcerned and therefore ill-prepared for retirement ${ }^{17}$. Noone et al. (2010) add that traditional gender roles place women at the mercy of their husbands' in accessing retirement benefits. Participants who were government employees returned home with mandatory financial planning, whereas a study by [15] suggests that preretirement education programs are needed for all workers and should be considered by all employers of labour. Some participants expressed disappointment in having lived their lives without proper planning, as did participants in studies done in South Africa [18] and also in Malaysia ${ }^{11}$, where respondents who had not prepared financially for retirement ended up with varying degrees of poverty, The South African respondents also complained of missed opportunities for education and poor possibility of providing for their families.

The Second World Assembly on Ageing established security in old age, which involves reaffirmed the goal of eradicating poverty in old age and building on the United Nation Principles for Older Persons (Madrid 2002). Giving endorsement to this goal, Ghana drafted a memorandum in 2003, which was given parliamentary approval in the period 2007 to $2010^{19}$. Participants responded that they did not know of any government plans for the aged. In the FGDs only two people, one being a former government employee, remembered that there was government policy for a subsidized National Health Insurance Scheme (NHIS) for the aged.

Care provision for residents of Kwawu Tafo in Ghana exists in concept and practice; for a society to be adjudged as morally admirable, it must, among other things adequately provide care for its members and territory ${ }^{20}$. From study participants, caring means that a person must be able to give and receive care for needs as they arise. Reportedly important caring needs are housekeeping, preparation of food, fetching of water and laundry services, regarded as activities of daily living, and financial remittance. Use of telephone and shopping were least reported as activities of importance, which could be because participants lived in proximity to their relatives and so did not see the need to learn the technology of handling mobile phones.

Ownership of a house is symbolic of authority over the household and is reserved for males ${ }^{16}$. The living arrangements of the elderly, when examined, fell within the context of changing traditional practice $\mathrm{s}$ that explain the tendency for old people to live on their own or in a non-extended-family unit. Nucleation of the family requires that persons attaining old age live with their children or spouse(s) but not with the extended family members they have never lived with [21]. The role of the family in Africa historically has been exhaustively presented by Apt (1999), who points out that, historically, African communities had well-articulated caring structures that preserved the quality of life of older people ${ }^{22}$ All participants reported living with a second or third generational family member; and even if the presumed relation was not living in the same household, they lived within a few minutes' walk from either a son or daughter. It has also been confirmed that most of the aged in Ghana live in a household owned by a live-in family member who is not necessarily aged, and that a high proportion of the elderly reside in dwellings, particularly compound houses, with limited access to sanitation facilities and amenities ${ }^{19}$. This is contrary to what participants in this study reported, they all confirmed that they owned their residence either by inheritance from bloodline, through government allocation that they later acquired, 
through their husbands (e.g. where the man died and left the house to them) or had built it when they were active. Consequently, elderly persons may not be recognized as heads of households, when they become economically dependent on household members ${ }^{19}$.

Participants in our interaction showed how closely interknit they were with others in the family, displaying bonds that showed intense relationships of care. The popular adage that 'when someone look after you until you grow your teeth, you must also look after that person until he/she loses the teeth' conveys the mind set of some of the participants creating mixed responses. Participants regarded the notion of institutional care with mixed feelings. Some felt that the traditional style of caring for the aged which was solely the responsibility of the family, nuclear or extended system, the programme would not thrive. Other thought it was worth trying to establish it but would prefer a daycare arrangement where they could still be in control of their properties.

In the one-to-one in-depth interviews, many participants were elated at the idea of institutional care but there was a different response when the same issues were raised in one of the FGDs. Some participants expressed strong disapproval, regarding the idea as shifting responsibility, getting the aged out of their homes or out of their way and exposing personal secrets to the public. Participants were unsure of the mode of operation of the programme and suggested that government must subsidize the cost, since they understood it would not be covered by health insurance scheme. Another participant thought the PI should use her initiative to organize and look for sponsorship for the programme. And if the programme took off and they were still alive, they expected that their children would pay because it was their turn to reciprocate care. Caring for an older family member is an investment of heart, time and money and the economic value of informal family caregiving is involving ${ }^{23}$. The life and well-being of the elderly people creates a vivid picture which shows that some of the elderly enjoy their old age while others do not. They lived comfortably, in their own house, surround by children and grandchildren. They were well-fed and had company throughout the day ${ }^{20}$. This description fits the participants perfectly.

\section{CONCLUSION}

The aged interviewed for this study indicated what, from their point of view, the main features of the study that is how the elderly prepared for ageing, how caring was done in their homes, awareness of government policies for them, and intention if institutional care was established as very pertinent questions. Institutional care was something new for most of them, and was initially rejected by all until they were given extensive explanation of its pros and cons. They all later asked for the programme to be established so that young men and women could be employed. Most participants expressed the view that it was time government had something good going for them. Although they were regarded as the custodians of culture, they all felt that it was very important to give the programme a try and that young people should be encouraged to plan for their retirement and old age while

Conflict of interest- the authors declare that they have no conflicting interest in this manuscript.

Funding for this research was the bursary provided by the scholarship secretariat of the College

of Health Science, University of KwaZulu-Natal, South Africa.

\section{Contributions}

IA conceived of the study, its design and write-up and BN checked for its relevance and ingenuity. IA undertook data collection and the preliminary data analysis (developing the themes and subthemes) and prepared the first drafts of the manuscript. BN read and confirmed the themes. All authors read and approved the final manuscript.

\section{ACKNOWLEDGEMENT}

We thank the University of KwaZulu-Natal, Health Science library that gave access to be used during data collection stage, and the financial support from the Bursary from the College Health Sciences. they were still active.

\section{REFERENCES}

[1] Zappalà, S., Depolo, M., Fraccaroli, F., Guglielmi, D. and Sarchielli, G., (2008) "Postponing job retirement? Psychosocial influences on the preference for early or late retirement", Career Development International, Vol. 13 Issue: 2, pp.150-167, https://doi.org/10.1108/13620430810860558

[2] Lee, W. K. M., (2003) Women and Retirement Planning: Towards the "Feminization of Poverty" in an Aging Hong Kong, Journal of Women \& Aging, 15:1, 31-53, DOI:10.1300/J074v15n01_04

[3] Donaldson, T., Earl, J. K. and Muratore, A. M., (2010). Extending the integrated model of retirement adjustment: Incorporating mastery and retirement planning, Journal of Vocational Behavior 77 (2010) 279-289: doi:10.1016/j.jvb.2010.03.003

[4] Ogunbameru, L. A. \& Bamiwuye, S. (2004) Attitudes toward Retirement and Preretirement Education among Nigerian Bank Workers, Educational Gerontology, 30:5, 391-401, DOI: 10.1080/03601270490433594

[5] Ogwumike, F. O. and Aboderin, I., (2005). Exploring the Links between Old Age and Poverty in Anglophone West Africa: Evidence from Nigeria and Ghana, British Society of Gerontology, Generations Review Vol. 15, No. 2, 7-15 
[6] Moen, P., (2012). Retirement dilemmas and decisions. In J. W. Hedge \& W. C. Borman

(Eds.), The Oxford handbook of work and aging (pp.549 - 569). New York: Oxford University Press

[7] Gauvin, F. P. \& Lavis, J. N., (2013) Dialogue Summary: Improving End-of-life Communication, Decision-making and Care in Ontario. Hamilton, Canada: McMaster Health Forum, 11 September 2013.

[8] Binswanger, J. \& Carman K. G., (2011), How real people make long-term decisions: The case of retirement preparation, Journal of Economic Behavior \& Organization, 0167- 2681/ Elsevier B.V.: doi:10.1016/j.jebo.2011.08.010

[9] Stango, V. \& Zinman, J., (2009). Exponential growth bias and household finance. Journal of Finance 64 (6), $2807-$ 2849.

[10] ILO, (2014), Social protection: In sub-Saharan Africa, only one in five older persons receives an old- age pension, World Social Protection Report 2014/15, Annex IV, table B.9

[11] Ng, T., Tay, W., Tan, N. and Lim, Y., (2011), Influence of Investment Experience and Demographic Factors on Retirement Planning Intention, International Journal of Business and Management, Vol. 6, No. 2; 196-204

[12]

[13] Joo, S. \& Grable, J. E., (2005). Employee Education and the Likelihood of Having a Retirement Savings Program, Financial Counselling and Planning, Volume 16 (1), 37-50.

[14] Helman, R., Greenwald. M., \& Van Derhei. J. (2007). The Retirement System in Transition: The 2007 Retirement Confidence Survey, EBRI Issue Brief No. 304: 1-29

[15] Ogunbameru, L. A. \& Bamiwuye, S. (2004) Attitudes toward Retirement and Preretirement Education among Nigerian Bank Workers, Educational Gerontology, 30:5, 391-401, DOI:10.1080/03601270490433594

[16] Van der Geest, S. (1998), Yebisa wo fie: Growing old and building a house in the Akan culture of Ghana,

Journal of Cross-Cultural Gerontology, 13(4), p 333-359

[17] Noone, J., Alpass, F. and Stephens, C., (2010), Do Men and Women Differ in Their Retirement Planning? Testing a Theoretical Model of Gendered Pathways to Retirement Preparation, Research on Aging, 32(6) 715-738. sagepub.com/journalsPermissions.nav DOI: 10.1177/0164027510383531

[18] Bohman, D. M., Van Wyk, N. C. \& Ekman, S. L., (2010), 'South Africans' experiences of being old and of care and caring in a transitional period', International Journal of Older People Nursing, 6, 187-195. http://dx.doi.org/10.1111/j.17483743.2010.00225.x

[19] Ghana Statistical Services (GSS)/Government of Ghana (GOG)/ Ministry of Employment and Social Welfare (MESW 2010)/(2012b), National Ageing Policy: 'Ageing with Security and Dignity', accessed through google scholar, June 2017.

[20] Van der Geest, S. (2002), Respect and reciprocity: Care of elderly people in rural Ghana, Journal of Cross-Cultural Gerontology, 17(1), p3-31.

[21] Ghana Statistical Service (2012). 2010 Population and Housing Census. Summary Report of Final Results. Ghana Statistical Service, Accra.

[22] Ramashala, M. F., (2001), Living arrangements, poverty and the health of older persons in Africa, Population Bulletin of the United Nations, Vol 19, 1-19

[23] Coughlin, J. F., (2007). Are You Ready for the New Older Workplace? Aging Baby Boomers \& the Evolving Role of Employers (AgeLab 07-03), Cambridge, Massachusetts: Massachusetts Institute of Technology

Table 1 Study sites and activities

\begin{tabular}{|c|c|c|c|}
\hline $\begin{array}{l}\text { Classification of sub- } \\
\text { district }\end{array}$ & Site & Activity & Number and sex of participants \\
\hline Urban & Site 1 & $\begin{array}{l}\text { One-on-one in-depth interview } \\
\text { FGD1 }\end{array}$ & $\begin{array}{l}2 \text { (male \& female }) \\
8 \text { (4 male \& } 4 \text { female })\end{array}$ \\
\hline & Site 2 & One-on-one in-depth interview & 2 (2 female) \\
\hline & Site 3 & One-on-one in-depth interview & 2 (male \& female) \\
\hline & Site 4 & One-on-one in-depth interview & 2 (2 male) \\
\hline Peri-urban & Site 5 & $\begin{array}{l}\text { One-on-one in-depth interview } \\
\text { FGD2 }\end{array}$ & $\begin{array}{c}2 \text { (2 females }) \\
16 \text { (6 male \& } 10 \text { female })\end{array}$ \\
\hline \multirow{5}{*}{ Rural } & Site 6 & One-on-one in-depth interview & 2 (2 females) \\
\hline & Site 7 & $\begin{array}{l}\text { One-on-one in-depth interview } \\
\text { FGD3 }\end{array}$ & $\begin{array}{l}2 \text { (male \& female) } \\
16 \text { (16 females })\end{array}$ \\
\hline & Site 8 & One-on-one in-depth interview & 2 (2 females) \\
\hline & Site 9 & One-on-one in-depth interview & 2 (2 females) \\
\hline & Site 10 & One-on-one in-depth interview & 2 (male \& female) \\
\hline
\end{tabular}

Field data 2016 *FGD: Focused group discussion 